\title{
STRATEGY OF EFFECTIVE MANAGEMENT FOR SMALL BUSINESSES AT DIFFERENT STAGES OF INNOVATION ACTIVITY
}

\author{
Dr Victoriia Nikolayevna Ryapukhina* \\ Belgorod State Technological University named after V.G. Shukhov, Russia \\ Emiliya Viktorovna Suprun \\ Belgorod State Technological University named after V.G. Shukhov, Russia \\ Dr Yuri Anatolievich Doroshenko \\ Belgorod State Technological University named after V.G. Shukhov, Russia \\ Dr Sophia Miroslavovna Bukhonova \\ Belgorod State Technological University named after V.G. Shukhov, Russia \\ Dr Irina Vladimirovna Somina \\ Belgorod State Technological University named after V.G. Shukhov, Russia
}

Proven by international experience appropriateness of the model of multiple innovation sources determines the urgency of the problem of development of small enterprises innovative activity. This paper examines the theoretical basis for attribution of "innovation activity" concept i.e. definition, types and stages of innovation, as well as analyzes the methodological aspects of effective management of the small business innovation. This study describes the main negative factors of innovation environment for small business and modern innovation strategies. The authors draw conclusions about effectiveness of application of innovative management strategies at different innovation stages and offer some measures to develop innovative intra-firm behavior.

Key words: Innovative activity, Innovation process, Innovation stages, Small business, Innovation management, Innovation strategy, An inter-firm behavior

\section{INTRODUCTION}

Nowadays the leading role in the innovative development is traditionally played by a linear model of innovation. According to the model developed fundamental scientific idea is embodied in applied research. The last are the bases of innovation which lead to advanced technologies. In XX century model worked well and would continue to occupy a worthy place in the developed countries. However, in Russia the framework of this model "fundamental science - research and development - production" was destroyed due to some objective reasons.

The "model of multiple innovation sources" has been gradually introduced in advanced economies in addition to the linear model. According to the model innovation can occur in any part of innovation system. Although research remains an important driver of innovation, they are no longer the only one. New knowledge is created, not only in public research organizations or research de- partments of large companies, but also in many business and social structures. In this regard, it is necessary to reconsider the traditional role of small businesses.

New everyday experience and activities of engineers, sales agents, other employees, as well as consumers are important contribution to innovation process. The emergence of innovations based on ideas and proposals coming from production, distribution and consumption sectors is typical for systems with developed relations between economic agents. Moreover, we must not forget that innovation process is not limited to technological sector, but also includes institutional, organizational and managerial innovations. This knowledge may not always be integrated into the existing framework of traditional concepts because they are the subjects' intangible assets employed in a particular industry. In this regard, companies should try to use this knowledge with maximum efficiency. Model of multiple innovation sources should be focused

* Belgorod State Technological University named after V.G. Shukhov, Russia, 308012, Belgorod, Kostukova Street, 46; 
on the mechanism of development taking into account diversity of elements and conditions for their creative interaction. Also, Nelepina and Nazarenko point out that should be focused on the path of economic growth, solving problem of availability of investments [11].

Problems of development of innovative activity of small businesses in the current conditions of economic activity are significant. It necessitates the search for new management decisions at various stages of innovation process. In regard with this research aim we first of all have defined the modern approaches to the concept and structure of an innovation enterprise, then, have considered modern strategies and ways to improve innovation management of small businesses. As part of our work, we also find interesting to present opinions of young researchers on this regard.

\section{ECONOMIC ATTRIBUTION OF "INNOVATION ACTIVITY"}

Innovation activity certainly is a complete complex concept. In this regard, there are many points of views about the nature of this phenomenon. According to Gribov, Gruzinova and Kuzmenko, innovative activity is an activity aims to find and implement innovation in order to increase range and quality of products as well as to improve technology and organization of production. At the same time, innovation involves identifying problems of a company, implementation of innovation process and innovation organization [06]. In our opinion, considering this approach applying to practice, the following definition is right: innovation activity is an activity for the creation, development, dissemination and use of innovation.

According to Safronov, innovation activity for development, implementation, development and commercialization of innovations include:

- Conducting research and development work for introduction of innovation idea;

- Laboratory testing, production of laboratory samples of new products, new kinds of technology, new designs and products;

- Selection of necessary raw materials and materials for new products manufacture $\mathrm{n}$;

- Development process of manufacturing a new product;
- Design, manufacture, testing and development of new equipment required for products manufacture;

- Development and implementation of new organizational and administrative decisions aimed at implementing innovations;

- Research, development and acquisition of necessary information resources and information support of innovation;

- Training, education, retraining and special methods of staff recruiting to carry out $R \& D$;

- Execution of works and purchase of necessary documentation for licensing, patenting, the acquisition of know-how;

- Organizing and conducting marketing research to promote innovation, and so on [14].

In accordance with the terminological system adopted by state statistics committee, innovative activity is an activity or a set of scientific, technological, organizational, financial and commercial activities aimed at commercialization of accumulated knowledge, technology and equipment; the results of innovation are new and additional goods or services as well as goods or services with new properties [12]. In accordance with the definition given in the regulatory documents, innovation (innovative) activity is considered to be activity on creation and use of intellectual product, launching new and original ideas into implementation of finished product on market (i.e. organization of examinations, implementation and replication of inventions, knowhow scientific and technological developments, scientific works, discoveries, industrial designs, trademarks, conduct research, design, development, marketing research in order to create models of new technology as well as patent-licensing) [09]. By definition adopted for conducting of financial operations, innovative activity is activity related to transformation of ideas (usually the results of research and development, or other scientific and technological advances) to a new or improved product introduced in the market, new or improved process used in practice or as a new approach to social services [1]. The group of authors headed by Azriliyan proposes to allocate six basic types of innovation:

1. Instrumental preparation and organization of production, production start-up and production development, including modification of a product and process; 
1. Training of personnel for application of new technologies and equipment;

2. Marketing of new products;

3. Acquisition of soft technologies from outside in form of patents, licenses, disclosure of know-how, trademarks, designs, patterns and technological services;

4. Acquisition of material technologies such as machinery and equipment related to introduction of products and innovation process;

5. Production planning, needed to create concept, development, production and marketing of new products and processes [01].

Innovation management is a separate area of management dedicated to issues related to innovative activity.

Innovative activity of an enterprise includes a number of successive steps, which also form stages of various cycle phases of a specific innovation project from idea to completion of development. Innovation stages in a particular project may vary depending on activity type of an enterprise as well as management system. However, there is the initial (pre-investment) stage, the implementation stage and the stage of work completion. This may seem obvious, but the concept of innovation stages is one of the most important for managers because it determines current stage of the most effective ways of innovation management. The first two steps of pre-investment stage make the greatest interest and importance. The stage of formation of an investment plan (ideas) is conceived plan of action. It is necessary to determine subjects and objects of investments at this stage as well as their forms and sources, depending on the intention of developers of business ideas. Study stage provides the following investment opportunities:

- Preliminary study of demand for products and services based on exports and imports;

- Assessment of the level of basic, current and forecast prices on products (services);

- Preparation of proposals on the legal form of a project and list of participants;

- Assessment of expected volume of investments on the integrated standards and preliminary evaluation of business efficiency;

- Preparation of preliminary evaluation of Feasibility Study, in particular evaluation of a project effectiveness;
- Approval of results justify the investment opportunities;

- Preparation of contract documents for design and survey work.

Stages of innovation associated with use of production capacity are considered to be the most productive. Stages of approval of intellectual property rights and certification in a country and abroad, innovative expertise, information and marketing, as well as investors search phase are the least efficient due to the current conditions of weak infrastructure in Russia and Serbia. At this stage, mobilization of intellectual and organizational resources and economic systems is necessary to bring together required infrastructure elements.

Ovcharova suggests that this problem has led to formation of a separate scientific discipline which is management of innovative projects and processes. Innovation process involves formation of plan preparation and gradual implementation of innovative changes. The concept of innovation process is broader than innovation and includes the following steps:

- Formation of priorities of innovation development;

- Formation and detection of demand for innovations;

- Search or generation, selection and refinement of innovative solutions;

- Introduction of innovations [13, p. 209.].

\section{PROBLEM OF EFFECTIVE INNOVATION MANAGEMENT WITHIN THE SMALL BUSINESS}

Innovations are the bases of efficiency, economic leadership and commercial success of innovative activity; it is a necessary and sufficient condition for the use of R\&D results. Economic relations should take into account the nature of innovative activity of a business entity. Economic interests underlie the formation of a system of economic relations. The system is adequate to requirements of modern business environment. Kochetkova points out the following as the principles governing composition of elements of innovation management in companies:

- Process of achieving the goal of innovation should be viewed as an ordered set of characteristics of intermediate states of study on its further development; 
- All components of innovation activities should be focused on achieving a common goal, formed on the basis of analysis of external needs;

- The unity of management, interconnection of all its functions, including forecasting, planning and operational management should ensure at all levels of innovation management;

- Formation of optimal composition and structure of innovation resources, identifying critical interactions;

- Use of the results of analysis of patterns and trends in innovation development;

- Determination of the nature and interaction of selection mechanism of factors prevailing in development of innovation at the transition from one stage to another [7. p. 81].

Organizational structure and mechanism of innovation management have a direct impact on effectiveness of production and business activities of a small business. There are criteria determining particular management system requirements such as full employment of staff, flexibility in resources use and compliance with market requirements. Tasks that arise in innovation management are fundamentally different from those that arise in normal course of repetitive routine in production process. There are large number of controllable factors in innovation projects unlike in investment ones. However, it imposes additional responsibility on a manager.

It is worth paying attention on opinion of young researchers on the considered problem. Chaadaeva believes that effective, conscious and purposeful management of intra-behavior is one of the most accessible resource for business development based on modern methods and practical applications of modern management. It is considered as a complex of human behavior and actions reflect the response to all circumstances of their existence in an organization as a social and economic system, including a form of individual and group activities such as various forms of communication [04]. The internal factors of formation of organizational behavior include attitudes, values and views of company founders, as well as collective experiences gained in development process. Socio-cultural environment is one of the most important external factor. There are various models of organizational behavior and, according to Chaadaev "the ability to identify a model of inter-firm behavior formed in a company is very important for a head of business because it allows not only to correctly interpret events taking place in an organization, but also to predict their development" [4. p. 335].

Innovation in management decisions determine that "an organization as a whole is getting increasingly interconnected and interdependent, but its constituent elements tend to increasing of independence and autonomy" [2. p. 110]. In these circumstances, on the one hand it is necessary to learn how to operate a set of independent variables, and on the other how to consider an organization as a "voluntary association of motivated members of a union aiming to servitude to their interests by meeting the needs of a particular environment" [2. p. 111]. In this case, it is advisable to consider the system as sum of its parts, i.e. integrity, elements of which are capable to make a choice. Thus, a goal is critical to this system. An object is determined if it can not only produce the same result in a variety of ways in unchanged environment, but also different results in the same or a different environment. The main objective of the system is to combine interests of motivated elements with each other. Unlike machines parts of which are sufficient to merge into a single entity only once, the process of integration in companies is the eternal problem and struggle.

Many researchers agree that there are three main approaches in modern control theory considering the role of a human factor: mechanistic, organic and humanistic. Bobova says that "evolution of a systematic approach has gone through several stages to the business management: from understanding an organization as an irrational system to the perception of it as a system with one mind, and finally to understanding an organization as a multiprogram system" [2. p. 111]. Management efficiency is due not much to the successful management, but also to staff members' interaction. Thus, members can cooperate simultaneously in one direction, compete in the other and have conflict over a third. With such a ratio of freedom and power of action, the whole becomes increasingly interdependent and its individual components aim to free choice and independent behavior. Standard methods for the management organization in an enterprise such as centralization, decentralization or are not effective compromise in this case and may even lead to negative consequences such as, respec 
tively, concentration of power and oppression, rejection of authority, chaos, stagnation and separation of powers. Duplication of power is the way out of the management situation for such a system. Empowerment is not a rejection of the authority or division of powers, it is duplication of power in all aspects of management.

This problem causes the relevance of an issue of leadership when it affects the rational, emotional and cultural aspects of organizational behavior. In this case, there are three areas of an intramanagement behavior: impact of a company's leader, organization and management mechanism, impact on organizational culture. According to Bobova, "to control the conscious and independent members of such a system new social calculus is needed while this control can be a learning function" [2.p. 111]. Ovcharova believes that structural changes and optimization of management processes can achieve very high efficiency of innovation [13]. Ideal scheme of intra-firm interaction does not exist, but in general, responsible and result-oriented administrative staff conducts strategic planning and oversees the implementation of the final stage; a development center conducts a search and generating of new ideas; an analytical center conducts screenings and refinement of ideas; a center of project management implements these ideas. Nowadays, the general trend is to accelerate organizational changes, the success of which depends on an innovative susceptibility of staff. According to Chaadayev, an inter-firm innovative behavior is "a system of formal and informal relationships in companies that contribute to the integration of all employees in a process of innovation implementation; that produce a positive reaction from staff on upcoming changes; that encourage initiative and creative approach to production targets, innovation, self-discipline and self-control; that motivate active involvedness in a process of innovation development" [4. p. 336]. Prerequisites for the formation of such behavior are:

- Open strategy and planning process of innovation;

- Creation of conditions for creative activity;

- Constant search for new ideas, thoughts, trends;

- Selection and hiring of competitive, innovative and active personnel with high professional motivation;

- Continuous training and competence of workers;
- Development of self-awareness and comprehensive support initiatives;

- Delegation of authority;

- Involvement of all employees in decision-making;

- Clear and open communication;

- High trust management;

- Recognition of rewards of each employee for taking additional risk and development of an organization.

An objective of an organization is to serve the interests of its members, while meeting the needs of the environment, so the openness, commitment, multi-dimensional and the emergence of counterintuitiveness are the five principles that work together as a coherent whole dynamic and define the basic characteristics and features of an organization, considered as a purposeful system [2. p. 111]. According to Bobova, these principles are an integral part of the third generation of systems thinking.

\section{MODERN INNOVATIVE STRATEGIES OF A SMALL ENTERPRISE IN CONDITIONS OF NEGATIVE FACTORS OF THE ENVIRONMENT}

The main limiting factors of innovation are limited resources and, above all, businesses' own funds. In the context of Russian reality innovations are originally made at their own expenses by introducing new products and developing new technologies. Zaikina argues in favor of the state form of support of innovative activity due to the limited financial resources of enterprises' own funds. Nevertheless, practice of business stimulation in economically developed countries suggests that a federal of budget funding covers no more than $15 \%$ of commercial realization of an innovation project [17]. In this regard, indirect stimulating methods of development of small innovative businesses make greater relevance and interest for the purpose of our study. However, nowadays the mechanism of indirect stimulation of innovation is also not sufficiently developed. Figurko says that there is a problem of access of small business to tax preferences, logistics subsidies, mechanisms for ensuring public order and other elements of state support, which are generally available to large enterprises as they already have high technologies on intellectual property rights [05]. Under these conditions, small businesses often can not and does 
not want to implement and invest in long-term risky projects, and is forced to choose shortterm strategy of profit maximization. Therefore, it is not expectable that a small business is able to participate in innovation projects in the early stages.

It is wrong to equate R\&D and innovation activities given the fact that input and involvement of businesses is different at different stages of innovation. For example, contribution of retooling at the stage of fundamental research is not essential due to limited resources despite the fact that, in accordance with the regulatory framework the standard definition of innovation gets almost any retooling where small businesses can participate. Ovcharova points out that the main barriers to effective development of innovative management are the following:

- A lack of necessary elements of an innovation process, which does not respect the principles of completeness and continuity of innovation;

- A lack of motivation to improve efficiency;

- A lack of organizational support;

- Low entrepreneurial culture and a level of protection of intellectual property [13].

Regulation of technology development of special economic zones is focused more on R\&D and practical implementation than on innovation process. However, success of a single innovative enterprise is insignificant for an economy in the absence of replication of a successful model of business innovation or innovation diffusion. Innovative activity of a SME should initiate creation of similar small businesses and new jobs on the principle of innovation imitation. Implementing this approach, massive small business will make a significant contribution to innovation economy although the contribution of small enterprises in development of its own scientific research is minuscule.

An enterprise strategy should comply with market conditions in modern conditions as well as a level of competition and its own resource potential. It is especially important to remember that a strategy of each firm is unique. According to Sazonov, company's is a generalizing long-acting model, which is required by a company to achieve its objectives with available opportunities [15]. Strategic measures are usually innovative as they include innovation aimed at development and involve the use of R\&D results.
However, it is advisable to allocate an innovative strategy in a separate block. In general, strategies are divided into active (technological leadership and simulation strategies such as following a leader, copying, dependence, improvement) and passive (marketing). Strategy of market leader implies introduction of basic radical innovation while a follower strategy envisages improving innovation.

Strategy of market launch of a small business should include creation of market value and effective strategic marketing as well as striving to customer satisfaction and product innovation. Compliance with these conditions will provide customers gain and retain. Meanwhile creating a sustainable competitive advantage is achieved through growth strategies and continuous introduction of process, organizational, managerial and marketing innovations. Strategy of conquest leadership position is based on creation of a new market value, differentiated marketing, close relations with customers, rapid release of new product categories and brands. In this case, creation of a sustainable competitive advantage is based on capacity-building, system, radical innovation process and creating of new business models. In contrast to the above strategies, survival strategy for winning and consumers retaining use price advantage and mass marketing of customer service, management of new attributes and product lines expanding. Resource generation, linear and gradual functional innovation and slight improvement in an old business model are used to create a sustainable competitive advantage in case of this strategy.

Kruglova classifies strategies based on company conversion, under which the author understands an unbroken chain of different reactions on changes in the environment and, above all, market for goods and technology [8]. This author identifies a strategy of partial change in product mix, a complete change of strategy assortment and strategy of change in technological specialization as well as adaptation of company priorities to market in stages of life cycle of technology or demand. Kruglova highlights the following among the innovative strategies:

- "Broad scan" is a strategy for development of new technologies capable for providing leadership in broader market;

- "Narrow scan" is development of technologies capable of providing leadership in one of the market segments; 
- Follow a leader strategy who indicates the main path of technological development;

- Strategy of technological leap, providing long-term competitive advantage [8.p. 89].

A special place in a strategic portfolio of small innovative businesses takes action and measures to neutralize or reduce the negative risk factors. Menyailova and Shulgin believe that "effective management of an enterprise in modern conditions is impossible without the use of special methods of analysis and risk management" [10]. Economic security of small business is provided by risk aversion, risk containment, risk sharing and risk compensation. Implementation of strategy of risk aversion implies rejection of implementation of innovative projects or preference of risk-free innovation. However, implementation of serious innovation does not happen without a risk, so small business which implements a specific project is often created in order to localize an innovation risk. Thus, there is a concentration of high-risk activities within one entity. Risk distribution occurs both in time and in space. The first is associated with the release of stages of innovation process, the importance of which we have already discussed in our work. In this case, for each stage are developed measures of risk compensation. The distribution of risk in space in practice is embodied in the diversification, co-financing, fragmentation of markets and procurement. In this case, for each stage measures of risk compensation are developed. Distribution of risk in space in practice is embodied in diversification, co-financing, fragmentation of markets and procurement.

Risk fighting is based on creation of material or information reserves. In this regard, search of guarantor is also used often. There is co-operation of a small business with a strong partner on the principles of equal utility. Risk of lack of demand for innovations is compensated by clustering or distribution of risk, as well as by providing small business orders from large companies and by production orientation of small businesses for subsequent replication of results by franchising. Reserves dealing with risks also include links and contacts as well as raw materials and funds. In this context, problem of management of internal assets and use of reserves of internal environment is important. The following may also be useful for staff training: innovation, rationality, risks, development of corporate culture, and so- cial development of an enterprise. In addition to adverse deterioration, risks can be unforeseen and unexpected such as unpredictable changes (i.e. discrete changes, thresholds, disrupt the communication channels, changes in individual or group psychology). A sufficient level to reduce the risk of innovation can not be achieved by traditional technological development. In modern conditions strategy of maximizing of economic and social benefits while minimizing the risks of innovation is the best for small businesses. The most rational innovative projects are considered projects that facilitate a holistic understanding of the consequences of their implementation.

\section{CONCLUSION}

"Innovations have a dual effect on dynamics of economic growth: on the one hand, they open up new opportunities for an economy expansion, on the other they make it impossible to continue this expansion in traditional ways. According to Schumpeter, innovation is accompanied by creative destruction of an economic system, causing its transition from one equilibrium state to another" [16]. Trubnikova says that competition of independent firms interested in business and product updates available on a market of competing innovation is the distinguishing feature of innovation economy. She also points out that any and all companies are advisable to develop high technologies, produce higher quality, improve production and business based on the latest progress [16]

Mensch and Klyaynkneht believe that an innovation incentive is often deterioration for a company, because there is no need to change anything when business is booming. [16] Until business makes a profit, the propensity to innovate is low. This hypothesis is confirmed by the fact that small businesses, which often exist on the brink of survival, are opened to all sorts of innovations promising economic growth and development of their business. This assumption is also confirmed by the conclusion of sociologists that the collectivist-innovative model of behavior is characteristic mainly for small businesses of up to 100 people. According to other scholars, improvement of financial situation of a company is precondition for the innovation implementation. Freeman and Clark say that only confident and forward-looking firms that are not afraid to risk innovations are the highly innovative [16]. In 
this case, an innovative incentive for large enterprises is the desire to monopolize a market and dictate their standards and the desire to consolidate its competitive position in the global market. Under this approach, innovation for small businesses, primarily mean development of new markets, seizure of product segments, setting of favorable prices, customer loyalty, as well as savings in production costs, productivity increase, and ultimately, profits increase.

Zaikina says that although according to statistics, more intensive innovation activity is characteristic of large enterprises, in practice it amounts only to minor improvements in existing products and production processes. The main motive is competition and the need for technical updates while the presence of really promising developments are initiated by only a small part of innovation [17]. Aspiration of small firms stimulates innovation and improves marketing activities of management processes and skills development. We believe that it is important to quickly identify problem areas in inter-organizational behavior with the help of on-line diagnostics in order to maintain this trend in an enterprise. It is also important to raise purposefully the level of innovative perception of the internal environment through series of training activities (e.g. workshops and trainings for managers) and formation of a mixed approach of working time organization. In this regard, Ovcharova believes that it is necessary to work towards strategy development, organizational processes, resource development, motivation and corporate culture (i.e. needs identifying for innovation brainstorming methods, survey experts and technology audit, analysis of existing solutions, development of channels to attract ideas, and then filtering ideas, creation of information sites open discussion), creating the institution awarding [13]. Bozhkov believes that a good incentive for increasing innovation activity of small businesses is to fix quantitative and qualitative goals of innovation development at various stages in documents [3]. In addition, according to experts, the following tactical measures increase the likelihood of introduction of innovative products by $15 \%$ : assignment of a responsible manager, creation of units which propose innovation ways, and collegial decisionmaking body for implementation of promising innovations by employees outside an organization. According to the results of our study, we can say that motivating factors for small business in- novation are also long-term technological priorities, optimal ratio of public-private partnerships and financing, effective innovative structure, distribution of non-technological innovation in the information and communication areas, increase of staff mobility, introduction of complex interdisciplinary and inter-industry innovation, and open innovation.

\section{SUMMARY}

Today, as the experience of developed countries show, "multiple sources of innovation" are advisable to be developed in addition to the traditional "linear" model of innovation process. In this concept of innovation, by which we mean the activities on creation, development, dissemination and use of innovation, the special role played by small businesses. Modern business environment, and such negative environmental factors as lack of own funds for implementation of innovative projects in particular, calls for creation and implementation of new strategies for the development of small enterprises. Currently researchers in this field have identified a number of innovative development strategies suitable for small businesses, including a special risk management strategies and effective management in an organization. It is advisable to implement a variety of strategies and not to expect the same effect and result at different stages of innovation. The ability to select and implement innovative strategies is the main function of modern management. In our opinion, improving the efficiency of management within a small business requires a review of traditional approaches to governance in favor of the theory of systems mentioned above which allow to take into account and take advantage of the creation and development of innovative models of intra-firm behavior.

\section{ACKNOWLEDGEMENTS}

The article was published with the financial support from Ministry of Education and Science of the Russian Federation within the framework of state assignment to the project \#26.1511.2014K "Theory and methodology of managing innovational and investment processes in small business enterprises." 


\section{REFERENCES}

1) Azriliyan, A.N. (1999) Accounting dictionary. Institute of New Economy, Moscow.

2) Bobova, K.N. (2013) Theoretical aspects of an innovative enterprise as organizational system. Scientific and Technical Journal "Bulletin of BSTU named after V.G. Shukhov", 3, 110-112.

3) Bozhkov, Y.N. and Kondrashov, E.A. (2012) Some aspects of the innovative development of enterprises. Scientific and Technical Journal "Bulletin of BSTU named after V.G. Shukhov", 2, 92-94.

4) Chaadayeva, V.V. (2010) Management of innovative behavior in a modern organization. Collection of Scientific Papers "Actual problems of economic development", BSTU named after V.G. Shukhov, Vol.2, 334-338.

5) Figurko, A.A. (2010) Development of innovative small business sector. Collection of Scientific Papers "Actual problems of economic development", BSTU named after V.G. Shukhov, Vol.2, 311-315.

6) Gribov, V.D., Gruzinov, V.P. and Kuzmenko, V.A. (2013) Economy of an organization (enterprise): a textbook for students, 5th Edition, SPE, Moscow.

7) Kochetkova, O.V. and Doroshenko, Y.A. (2005) The system of innovation management in companies. Proceedings of the International Scientific Online Conference "Actual problems of the economy reforming", Belgorod, Russia, 77-81.

8) Kruglova, N.Y. and Kruglov, M.I. (2003) Strategic Management: a textbook for universities. RDL, Moscow.

9) Letter of Innovation Council at the Council of Ministers of the RSFSR at19.04.1991 n 14448 , the Ministry of Finance of the Russian Federation at 14.05.1991 n 16/135B "On innovation (promotional) areas".

10) Menyaylova, E.A. and Shulgina, D.N. (2007) Risk management as a condition of innovative security providing. Proceedings of the International Scientific Conference dedicated to the 50th anniversary of BSTU named after V.G. Shukhov, Belgorod, Russia.

11) Nelepina, I.Y. and Nazarenko, N.T. (2006) Economic growth through innovation. Proceedings of Russian Scientific Conference
"Actual problems of socio-economic development of Russia”, Voronezh, Russia, 25-31.

12) Nikolayevna Ryapukhina (2011) Indicators of innovation. Higher School of Economics, Moscow.

13) Ovcharova, N.V. and Shchetinina, E.D. (2014) Organizational aspects of management of innovation processes and projects. Collection of Scientific Papers "Actual problems of economic development”, BSTU named after V.G. Shukhov, 207-216.

14) Safronov, N.A. (2008) Economics of Enterprises. Yurist, Moscow.

15) Sazonov, D.G. (2006) The main approaches to the classification of innovative strategies. Proceedings of the International Scientific Online Conference "Improving management mechanism in modern conditions", Belgorod, Russia, Vol. 2, 86-93.

16) Trubnikova, Y.V. (2006) he role and place of innovation in an enterprise. Proceedings of the Third International Student Forum "Education, science, production", Belgorod, Russia.

17) Zaikina, K.M. (2006) The problem of innovation in enterprises at the present stage of production development. Proceedings of the Third International Student Forum "Education, science, production”, Belgorod, Russia.

Paper sent to revision: 17.01.2015.

Paper ready for publication: 15.06.2015. 